Volume 7, Issue 1, 1-6 Pages

Research Article | Open Access

ISSN (Online)- 2378-7031

DOI :

\title{
Studio Ghibli and Japanese Soft Power
}

\author{
Anurag Roy
}

Kaveri 270, Mahagunpuram, India.

\begin{abstract}
For about forty years, the projects of "Hayao Miyazaki" and Studio Ghibli has been entrusted all over the planet as the pivot of Japanese medium of animation. Studio Ghibli is dubbed by its admirers as "the Walt Disney of the East", Hayao Miyazaki, the director, has generated movies that captivate individuals of every age range. Fairly, Miyazaki's whole filmology courses together with his peculiar unique beliefs; from his conservatism to his anti-Western Capitalist stance, his views of non-aggression, his interest with social affiliation of humans and the objectives of affection and fairness being innate to his read of humankind. His projects have additionally been utilized for numerous purposes- together by the Japanese administration and business-media bodies - to thrust consciousness of, and enlarge the need for, Japanese labels, media (specifically anime), and other cultural products. It is similar to how America utilized its soft power through Hollywood. Japan's mastery of soft power and its national stigmatization actions are in need to conform to uncertain domestic and international problems, together with economic and natural calamities, and even pessimistic global impressions too that were created after Japan carried it's Pan Asian project in the region replacing one type of brutal colonial power with another. Nevertheless, these actions point to position Japanese product - be they media or businesses in an exceedingly empire of distinctive individuality and higher-ranking quality. These programs have for the most part been thriving in advancing Japanese traditions and product as being innately cool. Anime and its related product set up a principal nucleus to the attractiveness of Japan as a holidaymaker's landing place and as a creator of media/consumer product within the brains of international viewers.
\end{abstract}

\section{INTRODUCTION}

The following paper is predicated on a review of Miyazaki's most famed animated movies namely;

- $\quad$ Nausicaa of the Valley of the Wind

- Grave of the Fireflies

- Porco Rosso

- $\quad$ Spirited Away

- $\quad$ From Up on Poppy Hill

- $\quad$ The Wind Rises

These movies mirror Miyazaki's philosophical metaphors relating to peace and war similarly. Also, about the environmental destruction that has had a significant impact on the history of Japanese animation. There are variety of earlier studies that contend with these films in terms of literature, film studies, ecology, faith and cultural studies. This paper would specifically build an effort to link these movies to Japan's effective use of Soft Power Propaganda termed as the 'Cool Japan Project'.

\section{CULTURE AS SOFT POWER}

The social scientist "Clifford Geertz" mentioned culture as something expressed in symbolic forms by means with which men communicate, perpetuate, and develop their information concerning and attitudes towards life. Another thinker Jack Snyder has termed culture "a set of semipermanent elite beliefs, attitudes, and behaviour patterns embedded into a particular mode of thought." Culture could be a difficult word, notably once it's employed in the context of the modern tutorial discipline of mediation. Culture is typically used to distinguish one's identity from a certain lot and it's vital to notice here that culture is unfixed and reworking in a way, therefore we can say that it's relative, it's typically narrated in an associate essentialized and fixed way to reproduce cultural form of government domestically as well as internationally. Thus, the conception of culture is usually used and abused by the powerful so as to decriminalise their dominance. Culture is mentioned largely in terms of 'soft power' in modern International relations. Joseph Nye initiated the enlargement of this idea in IR.

The conception of Soft Power was introduced in 2004 by 
academic Joseph S. Nye in his book: Soft Power: The means to Success in World Politics. Within the book, Nye describes two alternative ways states tend to develop so as to influence each other. Whereas some type of State and its people tend to use compliment and charm so as to attain their goals, others use brute force or threats. The first one is an associate example of somebody using active Soft Power whereas the latter is associate example of mistreatment inculcated in Hard Power. There are many ways in which governments will, or do use Soft Powers, and there appears to be certain countries which pay a lot of attention towards what Soft Power is and the ways through which it may be utilised. Japan is one of them. The Governments involved are able to carry out the desired results in varied ways of influence through varied strategies. As an example, many of us are interested in the happenings of US due to our interest in Hollywood and also the movies created there, we can say that to a certain extent they are responsible for us to know their culture. The federal government of the US has realised this and uses that to its advantage by generating great amount of cash to Hollywood, every year. Soft Power is defined as the power to induce what you wish through attraction instead of coercion or payment. due to that, it's tougher to use. The only drawback with the usage of Soft Power is that there's no guarantee that it'll work as supposed. We can have an added drawback with Soft Power which is that states won't find it irresistible, since people's interests are varied, it's really tough to aim it at an oversized cluster, because what influences one person won't have an equivalent impact on another.

To talk of Japan, the country has maintained a way of cultural distinctiveness. This distinctiveness allegedly derives from historical circumstances; Japan developed sure idiosyncrasies throughout its 250 years as an isolated and freelance nation within the Tokugawa Era. Those long periods of isolation, added to the evolution of a xenophobic mindset as the Japanese saw their way of life as the most complex and edified in whole East Asian region. One residual impact apparent nowadays is that the continuation of the Emperor System, that dates back to the origination of the state and have become the cornerstone of Japanese culture. This emperor system was demonstrated as god's will and Japan's destiny to rule over the entire Asian region. The formal originality of Japan's pop-culture, like the manga (cartoons) and anime (animation films) creative genres, is heavily influenced by ancient kinds of art in Japan, like emakimono. Japan's supposed distinctive ancient and common cultures representa good chance for students and also the government to extend their presence within the world, and that they have tried to include this idea into Japanese policy through- soft power. Soft power has so been inextricably joined with the promotion of national self-identity, that thinkers elaborate as 'brand nationalism', within which culture is used to boost the political and economic 'brand image' of the country. Complete nationalism has grown up to dominate the modern political landscape in Japan. It not only solely promotes and reinforces Japan's presence internationally; however, it additionally fosters the domestic ideal of a 'good Japanese' person - particularly, one who is considered to be natureloving and eco-conscious - this we can conclude on the alleged basis of the Japanese heritage that values nature and peace. Complete nationalism has additionally been going on to dominate political economy; as an example, the Japanese motorcar industry's hybrid automobile production and also the electronic industry's efficient electrical appliances are currently perceived as product of the inherent Japanese national character. A 'good Japanese' is additionally depicted as a peaceable entity who follows ancient knowledge and conventions and who generally is aware of what's right and what's wrong. This knowledge allegedly comes not from the rationalist religious doctrine espoused by the Western tradition but however from the information stock which is still within the normal and notably non-rational ways of life and is transmitted from Japan's past. Also, Japan has turned its eyes towards soft power due to its lack of self-confidence in international politics that arose with its wrongdoings in the post-world war II period.

\section{MIYAZAKI MOVIES AND PERCEPTIONS}

The animated movie "Nausicaa of the valley of the Wind" that first got out in 1984 gives us the glimpse of what it means to be trapped inside of the conflict of the Cold War. In its throughout history the US and also the Soviet Union were competitive within the sphere of development of nuclear weapons, followed by the UK, France, and China. The film reflects Miyazaki's philosophical metaphors concerning peace and war and also the environmental destruction and has had a significant impact on the history of Japanese animation. The film is said to reflect two supreme themes of 'nuclear war' and 'radioactive contamination' and offers North American country a glimpse of post-apocalyptic world. The film deals with social and world issues like nuclear weapons, nuclear war, and environmental destruction in rather inventive means. The story of the film is that of a fictionalized imaginary world which is 1000 years later, once the tip of the economic civilization is destroyed by the ultimate war in "Seven Days of Fire". Then we've got "Grave of the fireflies" which is designated as the greatest anime film ever created. For any of Miyazaki movies is not a kid's picture, and this one it's a devastating war film that has the power to naturally force a mature man cry, sob and express their feelings. This can be because of the actual fact that it's all based on a real story and automatically makes it a lot more agonizing and troubling. The movie tells us that war is dangerous not simply because of bombs and death, but at the same time one cannot forget of the sufferings people are forced to bear as its consequences. The tragedies of the animated movie measure an instantaneous result of warfare in the world war II. The film doesn't question the "rightness" or "wrongness" of the war or its varied military engagements however it shows that once powerful folks use them while 
not standing as tools and pawns, the fatal accident may be devastating. One will justify some wars on the premise of serving a "greater good" like how Japan did under the garb of the vision of a Pan Asiatic identity and to be honest it doesn't subtract the terrible truth that even the foremost righteous success can have its share of innocent victims.

This film "Porco Rosso" may be classified as an anti-war informative movie. Hayao Miyazaki has been perpetually keen on airplanes that existed throughout the world wars. Over this, the film conveys the vital memory of war, particularly the interwar era and also the post-Cold War world. 'Better to be a pig than a fascist', this Porco speaks once he's at the bar which shows that, Porco, who once used to be a local war hero, is set to become and stay a pig as a result of the firm belief that he didn't wish to be a fascist who supports nationalistic hawkishness making his point. Through the risible and romantic animated plot, this picture conveys Miyazaki's antiwar pacifism, non-killing philosophy, and also the memory of war. The film "Spirited Away" turned out to be one in all the other Japan's preferred and most fetched films like 'Your Name' and 'Weathering with You'. The movie is praised by critics as 'one of the foremost vital animation movies of all time,' it has achieved several global accolades, as well as the honour in the category of Best Animated Feature of 2003 "Academy Awards". Miyazaki's main interest in the movie is to comment on 'the Japanese fixation with intense shoppingbased laissez-faire economy with victimisation of Japanese bubble economy as an ulterior theme. The vital point here is that the picture depicts the age before the lost decades of Japan. The picture has this special character Kaonashi, who becomes 'an embodiment of client greed.' Kaonashi consumes so as to fill the emptiness that's inherently a part of his being, he's a miserable beast with having no persona, and he will solely interact over the tone of somebody that he has enveloped into his being by consuming them. This excessiveutilization leads Kaonashi to a damaging violence once his genuine need, the corporate and warm heartedness of "Chihiro"- the character, is refused to him. The sole approach with which he will come back to traditional form is for him to remove all that he has injected within himself, this happens when Chihiro supplies him wizardly drugs, delivering the creature to his concerning natural worthlessness all anew. This shows Miyazaki's critique of the Capitalist consumerism society in an utterly beautiful way.

The film "From Up on Poppy Hill" is depicting the lives of Yokohama in 1963. The story takes place in the very Japan which's selecting itself up from the devastation of warfare II and getting ready to host the 1964 Olympic Games - and also so the collective mood is one of all optimism as well as conflict because the new generation struggles to embrace contemporaneity and throw off the shackles of the countries troubled past. The animated film is that of a combined effort of legendary animator Hayao Miyazaki, who co-wrote the film, and his son Goro Miyazaki, which is his second animated film as a director. It's a story concerning the primary generation of the new Japan that sprung to life when warfare of the World War II is over. This we can see through as examples from the movie like, the high-school students effective handling of Ham radios to speak outside of their borders, discovering literature, and fighting the authorities by organizing the scholars to revolt in a very peaceful approach. When Japan was defeated in world war II, the foremost important topics were the social reform which was caused by the Occupation Forces, and Economic Reconstruction. The film terribly \& fantastically touches every of those topics. The Occupation policies were to deal with the weakening economy and were ranged from tax reforms to measures geared towards prevention of dominant inflation. However, the foremost significant issue was the shortage of raw materials that were needed to feed Japanese industries and markets for finished product and fortunately for the country came the Korean War as Japan became the principal depot for international organisation forces. The Conflict conjointly placed Japan firmly with the range of the U.S. defence perimeter in Asia, reassuring the Japanese leadership that regardless of the state and of its military, no real threat would be created against Japanese soil. The picture "The Wind Rises" that came out in 2013 and which tends to exemplify the theme of 'difficult time to live' throughout the Japanese history and how the folks suffered from the utterly devastating Kanto earthquake that killed 10,000 people in total, also the worldwide economic depression that resulted in high state rates, and also the spell of time following the Second world war warfare. Miyazaki explicit that the film doesn't plan to denounce war or to beautify the Japanese Zero Fighter plane, however it tends to portray a Japanese young man who pursued his dream and cherished his love despite the troublesome age he lived in. Miyazaki may have supposed to form an unpolitical animation, but his viewpoint on Japan's involvement within the Pacific War was that "it was not right since the very beginning" however conjointly it is useless to make Jiro accountable for it. Some movies convey narratives and aspects of Japan's period of time and pre-war history and also this film may be classified mutually of the movies as storytellers of war. To retain war as a memory, it may be fictionalized and this memory may well be totally different from nation to nation, and also from people to people but there's little question on the theme that The Wind Rises actually contains the memory of war as a message for peace in relevance for Japan's 'war responsibility' over the Second World War warfare. Moreover, Miyazaki argues that Japan shouldn't begin a conflict with alternative Asian countries in up-to-date times by rewriting its peace clause that is the Article nine of its constitution.

\section{WE DON'T SEEM TO BE THE VICTIMS THEME}

Another of the famous director's nice issues is outlining higaisha ishikior 'victim mentality'-that the director perceived was preserved by successive governments. Japanese ethno- 
sociologist "Boye Lafayette De Mente" writes: 'This longstanding thing is symbolic for the nationalistic people of Japan who account others for their own issues and even for any of their activities that ends up in antagonism or condemnation'. De Mente asserts that this tendency of accounting others for own offense exists and it exists on all levels of society, from personal interactions up to the company or community level. This, successively is commonly remodelled into a kind of exceptionalism where it is forbidden for the Japanese nation and culture to be criticized by outsiders, be they a social/ ethnic minority or an overseas nation. De Mente points out that the concept of "higaisha ishiki" found its origins throughout the U.S. occupation of Japan when the world war two warfare was going on and it was imposed among the national consciousness once the U.S. forced Japan to adopt a pacifist constitution and took away the Emperor from any position of authority- one thing that several Japanese folks found deeply undignified and insulting nonetheless were unable to readdress. Instead, several of the people in power in Japan, particularly nationalist politicians and media creators, promoted the concept that Japan was a victim of circumstance and also the brutality of the atom bomb along with the unjust crimes which were inflicted upon the innocent public, therefore making an environment of exceptionalism and denial that helped breed a victim mentality. In a long time it has been a standard follow among Japanese news and fictional media to account everything on some external influence, which are sometimes foreign in origin, for issues like society's ills, or social minority, in similar ways even otaku geeks, and to assert that the countries people, and its community as an entire, don't seem to be liable for the plight of Japanese community however fairly they are the pawn of occurrences or the plan that have been played from out of doors of the country. Thinkers recommend that so as to deal with the lengthening of this Victim frame of mind, Miyazaki expelled several of his fictional narratives from a rigorously Japanese neighbourhood, sometimes the man shot his movies in a very practical nonetheless outlandish adaptation of post- automated industrial Europe - as seen in Porco Rosso as well as Howl's Moving Castle. Miyazaki conjointly dwells and supersedes the chances of victimization by making his heroes take affairs in their own hands not just for their own activity but even for the activity of others.

\section{THE “LOST DECADE” OF JAPAN AND WITH IT THE "COOL JAPAN"}

A little over three decades ago, in 1989, Japan was finishing a decade of wonderful economic performance. Its 3.9\% average annual rate of growth of gross domestic product, which was slower than what it had achieved in any earlier decade since 1950, was still considerably higher than the performance of the world's different advanced industrialised economies. Throughout this same decade, equity costs rose six-fold and land costs over four-fold. With equity and land costs multiplying dramatically, in 1989, several economists were ready to argue that the new valuations were more of even if we see by Japan's economic fundamentals. The Country's distinctive national economy was seen as operating thus well by comparison with those of different major economies with Japan even being addressed as the "Communist nation that works" however massive bubbles developed within the property and stock markets in the period of the late 1980s. This collapse in the diode sectors is actually responsible for sluggish growth within the Nineties, often referred to as the "lost decade". Contrary to standard perceptions, Japan's lost decade wasn't on the entire a type of economic contraction; this is because GDP growth averaged around $1 \%$ annually. However, this was abundantly less than previous decades. Additionally, long effects from the decade's monetary crisis still plague the economy to the present day. The exploding of the late 1980s property and stock exchange bubbles is responsible for banking and various companies' debt crisis.

The main reason for this to happen are often found during the important fall of the monetary market. Within the economic bubble of the 80s, banks were disposing additional and more cash and didn't paid any attention to the client's capability to pay them back. Ultimately, this state of affairs couldn't carry on, and therefore the national economy folded. Once the Bank of Japan raised the inter-banking disposition rate to stabilize the market which were stuffed with dangerous loans, the chimerical economic scenario began exploding. As property and stock costs each fell, assets of firms and banks were currently of no value in comparison to their liabilities. Low to no equity and decreasing price of assets meant that monetary establishments like banks and insurance firms were in debt, which includes major national banks. The economy crashed, and monetary establishments were facing serious losses. As a result, many of the estate costs plummeted, stock costs were falling speedily, and dangerous loans became a burden on the entire system. The govt bailed the banks out, however even with their facilitation, the banks regularly continued to figure below debt. Several firms were in hassle additionally, but they might now not acquire credit, on the other hand people were losing their jobs and so now they were not liable to pay any cash or even their debts, because they had no source for it left. Japan was troubled. The property values were coiled, interest rates were happening, and the state's Joblessness was rising with heaps of individuals being now used to work as parttime because of firms which were regularly cutting prices wherever they got a chance. GDP was declining or can be called stagnating. A protracted stagnation that followed has left lasting effects that the country still endures these days. The implications of the depression were still wide felt well past the 10 years, a replacement decade came, however the trial wasn't over nonetheless. Today, Japan remains fighting deflation, low-interest rates, and weak banks despite the fact that the impact of the lost decade has lessened, there lies new challenges ahead as there are still many people who are operating in part-time jobs because of the lack of stability 
of the economic sector. At the top of an awfully attentiongrabbing, turbulent decades for Japanese animation, we tend to saw the meteoric rise of Studio Ghibli and therefore the Cool Japan project applied.

For the previous couple of years, Japan has been attempting to market "Cool Japan" project. Well, there's no easy case for this idea since there are a couple of lot more factors that creates Cool Japan. There are unit selective subcultures in Japan that have gained some quality and have unfold popularity round the world, that area unit touches the younger adults within the world and consequently form the Cool Japan thing. The leading figure to market Cool Japan to the Western world was Aso Taro, one among Japan's former Prime Ministers, who was identified for having a strong feeling towards Manga and would scan it nearly daily. He was attempting to possess the govt to promote Japanese selective Psychedelia that had gained some quality and unfold popularity round the world and has affected several of the younger adults within the world. He believed that promoting these youth cultures would attract foreign folks to return to Japan. Among those things are: Manga, Anime, clothes, food, and electronic goods. Through effective use of its commerce and marketing of these products, Japan has managed to bring in finances and gain support from foreigners. Among Japanese cultural components, anime and manga are likely to gain more attention since they get pleasure from the foremost widespread international diffusion. In 1956, the far-famed Toei Animation was established and aimed to be the "Disney of the East". Far-famed animation directors like Isao Takahata and Hayao Miyazaki, who in their early years grew up in Toei, gave birth to a different far-famed animation studio named "Studio Ghibli". The largest distinction that can be made between Disney animations and Japanese anime is that of the content. If we talk of western animations which were like cartoons were specifically created and more focussed on kids. However, Japanese anime carries all aspects of life on the screen, several genres like sports, science-fiction, mythology, horror, and even adult content unit the topics. This facet of anime has multiplied the variety of target marketing and has reinforced its hand against Western vogue animation. Therefore, the "language" of anime is turning into additional internationalisation with every passing season.

Less people would argue if we look at the collective significance of both Miyazaki and Studio Ghibli and link it to Japan's international attempt to forecast a National grade competence through effective use of its media product. The utter importance of Miyazaki and his brand was most likely most clearly incontestable once the director decided to pull out from animation production in 2013. This led to the Japanese government issuing an announcement on how this might affect their national stigmatisation effort in particular the "Cool Japan agenda" with the motif of convincing stockholders that things are fine and would continue as before. The directors retreat from affairs gave rise to a real worry in several of the stigmatisation and soft power project lenders, and even perhaps a downward collision of the Japanese stock exchange market within the style of probably decreased media and commercialism deals. An announcement from METB (Ministry of the Economy, Trade and business) came which voiced that the Agency would ought to measure the possible influence of this affair against the country's national stigmatisation and soft power initiatives, particularly with reference of discharging Miyazaki's last of film, "The Wind Rises", and its pessimistic acceptance within the America thanks to the contentious inferior subject material as seen by the accepting audiences. Miyazaki along with the production house pushed a lot of greenbacks year by year into the Japanese overall economic wealth, not only because of the sales of product associated with the production house, still conjointly from external commercial enterprises from different parts of the world that land to Japan because of the association felt with the country through the director's work. Different programme investors, as well as different media rendering homes, have used the status of both the director and Studio Ghibli that is highly rated within the West to get commercial interests in their field. This is often typically achieved through pairing the film with another medium unleashed at various global film festivals, like for example when France produced the animated movie "Red Turtle", it got the label from Studio Ghibli just to draw most debate within the Japanese media and associated media product as a whole. Yet, whereas various other business investors seek to gain advantage through the directors complete and global status, he personally is not at all interested in developing this into a dependent relationship. The director is absolutely cognizant of this aspect of media selling and even of company support and the necessity to create the necessary conditions for any film to be successful.

At last, we need to answer why this Miyazaki brand is so powerful? The answer lies here that the director designs his movies in such a kind where he doesn't intend at any cost to inform the spectators as to what or How the things are going and even what is the exact way to assume things. To be fair, he politely asks the audience to do various things, to ask question to themselves, to meditate and to interrogate the views and agendas that they're presented with and constrained by far and wide in their respective lives. Over various strata, the director's main task is to fill up this assurance in his audiences so as to encounter the imagined truth that's in a way delivered by the assorted project encoder and venture capitalists who just like the inhabitants of Plato's representative cave, are attempting to convey other people out there that the image they forged depicts the real world whereas actually it is not. During all this falsehood the directors intelligent capability is he's able to capture minds across such a lot of stratifications of community and over all perimeters - be they topographical, communal or even political protecting his spectators against motive associated pedagogy while not depicting himself as an influencer who 
should be embraced and this has in duly manner helped the country gain a positive perception of a peaceful and delightful nation within the international world, well that's the flexibility of Soft and sentimental Power if used effectively.

\section{REFERENCES}

[1] ABEL, J. O. N. A. T. H. A. N. E. (2011). Can Cool Japan save Post-Disaster Japan? On the Possibilities and Impossibilities of a Cool Japanology. International Journal of Japanese Sociology, 20(1), 59-72. https:// doi.org/10.1111/j.1475-6781.2011.01148.x

[2] Bigelow, S. J. (2009). Technologies of Perception: Miyazaki in Theory and Practice. Animation, 4(1), 5575. https://doi.org/10.1177/1746847708099740

[3] The animeart of Hayao Miyazaki.(2007). Choice Reviews Online, 44(06), 44-3194. https://doi.org/10.5860/ choice.44-3194
[4] 강성우. (2016). "Cool Japan" as Japan's cultural diplomacy and nation - branding strategy. Journal of East Aisan Cultures, null(65), 215-241. https://doi. org/10.16959/jeachy..65.201605.215

[5] Iwabuchi, K. (2002). "Soft" nationalism and narcissism: Japanese popular culture goes global. Asian Studies Review, 26(4), 447-469. https://doi. org/10.1080/10357820208713357

[6] Shadow, 2015, 'Wings and Freedom, Spirit and Self': How the Filmography of Hayao Miyazaki Subverts Nation Branding and Soft Power.

[7] Bolin, G., \& Miazhevich, G. (2018). The soft power of commercialised nationalist symbols: Using media analysis to understand nation branding campaigns. European Journal of Cultural Studies, 21(5), 527-542. https://doi.org/10.1177/1367549417751153

Citation: Anurag Roy, "Studio Ghibli and Japanese Soft Power", American Research Journal of Humanities and Social Sciences, Vol 7, no. 1, 2021, pp. 1-6.

Copyright (c) 2021 Anurag Roy, This is an open access article distributed under the Creative Commons Attribution License, which permits unrestricted use, distribution, and reproduction in any medium, provided the original work is properly cited. 